\title{
Industry 4.0 and IoT: How to Improve the Knowledge for the Project Management before Carrying Out an Implementation
}

\author{
Gerardo Mena Caceres \\ Astilleros Navales Ecuatorianos EP, Vacas Galindo S/N y Vivero, Guayaquil, Ecuador
}

\begin{abstract}
The paper intents to give a perspective for amateur engineers who are related in company transformation from a current situation to the industry 4.0 and IoT implementation. The present work is focused on people without any kind of expertise or specialization of IoT or automation concepts, but due to the possibility of being involved in topics related to industry 4.0 have the needs to have any kind of basic knowledge in order to know if a small or medium enterprises need these kinds of new technology..
\end{abstract}

Keywords - IoT, SMEDs, project management, industry 4.0, knowledge management.

\section{Introduction}

From the XVIII century which defines the first industrial revolution not only the man has changed the ways of working, but has intended to develop new technologies and methodologies in order to support the current jobs and thinking about the future. These technologies have had its first approach in how to improve the productivity, focusing on the production that often is traduced in the manpower and machines.

Furthermore, each industrial revolution entails the development of other aspect around it such as: economical, societal, and technological as main factors.

DOI: $10.18421 /$ SAR33-07

https://doi.org/10.18421/SAR33-07

Corresponding author: Mena Caceres Gerardo, Astilleros Navales Ecuatorianos EP, Vacas Galindo $S / N$ y Vivero, Guayaquil, Ecuador

Email: gmenacaceres@gmail.com

Received: 17 July 2020.

Revised: 17 September 2020.

Accepted: 22 September 2020.

Published: 29 September 2020.

(cc) BY-NC-ND (C) 2020 Mena Caceres Gerardo; published by UIKTEN. This work is licensed under the Creative Commons Attribution-NonCommercial-NoDerivs 3.0 License.

The article is published with Open Access at www.sarjournal.com
Later, in the technological aspect the electronic and robotic were implemented during the third industrial revolution. This implementation made that the automated process grew up within the biggest industries and factories [6]. On the other hand, internet appeared which eased the world connectivity allowing the communication between systems [5]. that combined with the automatization bring the concept of industry

4.0.

The concepts of IoT and Industry 4.0 are related to the Industry 4.0 or intelligent industry which cannot be possible without the communication and connectivity of the things [3], [4]. Moreover, in the current days the concept of industry 4.0 involves not only the factories or production fields [2], but it also considers the supply chain, the innovation and the solution that a company can offer to the market/ customer. New innovative products will fabricated thinking in the possibility of its connection with the internet in the years to come, some examples of which we can see in the smartwatches and initial models of intelligent house or building, and that is why engineers and especially the companies which want to survive the next 20 years should think in the IoT and Industry 4.0 as the first point of departure in this new era.

Nowadays, the high level of information which is stored are major than before, and the information is variable which can come from the process and manufacturing systems, selling services, maintenance service, customer preferences, general data, and etc. These informations help to improve the processes within a company. Having this kind of information, some kind of possible troubles or fails within the industry can be prevented through the detection of not common result or having the expected information from the process, even the relationship between processes can be determined.

In addition, it is clear that nowadays the gap between the cyberspace and the real life is less than some years ago, the technology has developed to the point that the devices can inform about its functionality or state and make a decision according what they need by itself asking the user or offering them the best way to solve a technological issue. This 
information could be taken in advantage to solve possible interferences in the manufacturing system or the time needed to manufacture one product/service and its delivery. Besides, the industry 4.0 based on IoT is not only about tech, but also the management system within the company which requires and depend on some factors concerning the company, such as organizational changes, and those kind of changes should be managed according to the situation, but in many cases the engineers or middle manager do not know how to solve some issues, and the main problem is due to the lack of information more than the difficulty level of the problem. The foreseeing only is possible when the personnel involved in the implementation of new systems have any kind of information of it.

On the other hand, sometimes it is not easy to find an information about the points or factors which affect the transition from a current industry to the concept of industry 4.0 or how manage during or before of its deployment,. Meanwhile, the information of IoT increases causing that most of the engineers related with production do not have enough tools to try to understand the process behind the IoT systems, which are commonly managed by personnel with huge knowledge of IT systems.

\section{Scope}

In accordance with the aforementioned, the main scope is to show a general knowledge to understand the IoT and Industry 4.0, as well as the relationship that exists between them and the advantages that the new digital and automated era offers to the industry within a small and medium enterprises.

\section{Goal}

Our goal is to provide some points of general knowledge to help the amateur engineers or people who want to know about the necessary changes and some steps to implement IoT system. This paper will try to show some different fields of knowledge and establish the needs of a company and the engineers before IoT deployment, giving a perspective from the point of project management.

\section{General Approach}

To determine the possible changes or effects that a medium-sized company might require prior the time of IoT implementation, it is necessary to know certain conditioning or necessary aspects of the new system to be implemented. Once having knowledge although not deeply one, at least in a general idea, we could establish a priori the possible collateral effects and take actions before they occur. It should be mentioned that "collateral effects" refer to the aspects which are not necessarily technological or that are directly related with automation or IoT, and therefore the connotation refers to those areas of management and administration within a company, such as: human resources, organizational structure and information management.

\section{Advantages of IoT implementation}

\section{From Manufacturing and Production Perspective}

The main objective of the industry 4.0 and the IoT is to get real information at the time that we need, and the information of what we expect [9]. This means that the industries and systems can be: simplified and streamlined, reducing the likelihood of accidents or failures. These points are a great feature that the whole industry looks for when it makes the production of goods, which is to have a competitive advantage over others.

\section{From Design/Engineering Perspective}

According to current and new trends in the use of the internet and the connectivity that it offers us, the concept of products and its development has also evolved. We have to start from the fact that certain products are changing and have greater incidence in the diary life are focused on the technological development of them, in which these products allow to be linked with others around them. Then we can say that certain products have evolved from having only physical components to complex systems that allow connectivity between them.

The establishment of new paradigms within the initial phase of design and development of a product allows us to cover some of the most important aspects presented by companies around us, and that they have a high level of importance within the companies' performances, such as:

a) Personalize/Customize

b) Monitor Condition/Operation

c) Monitor Environment

d) Autonomous

\section{Supply Chain and IoT}

As it was mentioned previously, the IoT implementation offers outnumber of benefits without taking in account the creation of stream value with the client. But it is necessary to mention that without a derivable value from the enterprise side, it is not possible to increase the business. Further on, the IoT implementation gives us [1].

a) An Information transparency, by which Information systems have to be able to make 
copies of the real world by improving their models with sensor data.

b) There is a Technical Assistance to humans, showing the information required, which enables us to easily understand decision making and actions, helping tasks that could be unsafe or exhausting.

c) Decentralized or autonomous decision making opens the possibility for the device systems to make decisions and perform tasks autonomously from the information created and the experiences learned by it.

\section{Steps to Improve the Knowledge for the Project Management}

It is evident that every manager or director has to evaluate the need to implement any kind of change in a company, especially if it is related to a technology group. Nine steps are suggested in order to improve the background and the knowledge of the possible project. Of course, conclusions are not included, however, every analysis has to have it.

\section{Mapping the IoT Objectives}

Mapping is the best idea to know where we are now and where we want to be, without this IoT mapping the goal and objectives of any deployment could be easily lost. In this point one objective should be chosen in order to simplify the process and know if the other ones have the same path or not. The main idea is to make a path, something easy to remember, which helps everyone to follow different points in order to develop an IoT project. Mapping also helps to show others the initiative route, this point is important when project managers have to show the project to the stakeholder and the team.

There are some literatures that can help us to make a road map. However at this stage recommendations and the road map do not have to contain a lot of information about the technical part (hardware, software, platform, sensor, etc.). At this stage it is more important that the road map is understandable, even to an operator. That is why writing down the objective or the goal becomes imperative.

Additionally, a mapping can be included, explaining how one will work in order to start, develop, and manage the implementation.

\section{Identify the Activities Carried out by the Company}

The starting point of all entrepreneurship is not only to know the different technological [7] solutions that the market offers in terms of global trends or in terms of industrialization processes, but to know the medium to which the analysis should be carried out and then implement a new technological communication system.

The recognition of the activities carried out by the company in a "micro way" (step by step) will help to understand its operations, and it is also closely related to the following points, since without this first activity, it is not possible to know the current conditions of the company.

\section{Looking for Support and Consultations}

If the idea of possible failures and errors that are made within a process already exists, and also as a company employee there is the interest of the implementation of new systems that allow the connectivity of equipment and machinery, and the most logical thing is to consult colleagues from other areas or departments for their opinion.

One has to bear in mind that in the process of data collection, and above all, trying to find flaws in processes can become complicated, since noting the errors within a value chain, not all people could see those findings "in good way", it is advisable to use certain techniques of approach and negotiation. For this purpose a reference and adaptation to certain concepts and recommendations from Richard Shell's book on the approach to negotiation, three (03) initial and essential points are to be mentioned: "planning, preparation, and having an attentive ear, which is what is based on information-based negotiation, which means getting as much knowledge as possible about the situation and from the other part". ${ }^{1}$

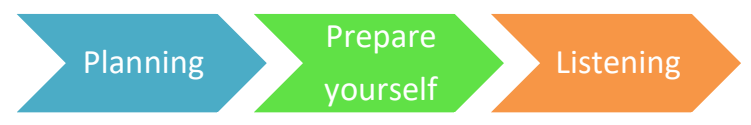

Figure 1. Fundamental Aspect of Negotiation based on Information

a) Planning refers to have clear objectives and information wanted, so that, at the time of the approach and request for information one does not wander or give back around a topic or points that can be unnecessary or deviate from the objectives. Planning becomes necessary even at delimit execution times, and it even determines the efficiency in information surveys, so that standards can be established for future implementations, even where costs are linked.

b) Prepare yourself, in other words: make a research about what one needs. For example, if it is the delivery area it could be the first step, read

\footnotetext{
1 Bargaining for advantage: Negotiation strategies for reasonable people, Richard Shell, Penguin Putnam Inc., Barcelona, 1999
} 
or find out in a general way what the process is about and what is the value of it, as well as the method that follows, such as: registration, labeling, and distribution. In this way we will have bases, upon which we are able to engage in a "conversation" with the person/people that we are going to interview. In addition, at this stage, you could organize your own ideas about what kind of information you expecti and want.

c) Listening - this is perhaps one of the most important points and one of the most complicated in communication and information collection. This part is about listening carefully all the information that the other party wants to tell. In the subject of effective communication, this is one of the fundamental pillars for an efficient and effective communication, where both parties (receiver and transmitter) offer clear and concise medium (message), and without a doubt while listening openly and without making value judgments support the generation of trust, which is what determines the future relationship or not of our search for information.

These points of recommendation are also given by virtue of the fact that a common mistake of some area managers or directors could be thinking that a team or a single person can solve the possible problems of the entire company and all its processes. This assumption cannot only be harmful, but even the full objective of implementation of "Internet of things" and M2M connectivity also cannot be understood without it.

\section{Identify the Problems to be Solved}

Given that the spectrum of the IoT is broad for the entrepreneurship of what we can consider a "generational change" within a company, one of the most efficient ways, and that in the end will be effective, is to demonstrate that the solution to the problems or change that one wants to achieve when producing a product or providing a service is with the application of the IoT.

This is the second consideration, and it is because not all CEOs of companies are willing to make a significant investment in the implementation of new technologies and ways to perform or control a job without having a "tangible" result of the investment. It is for this reason that identifying problems and bottlenecks, which can be solved by interpreting data in real time, even with obtaining data that support middle managers to make better decisions, becomes an attractive solution for the senior management at the time of allocating an amount of money for certain ventures.

The aim at this point is simply to recognize the business reality in order to determine the need of a certain level of automation greater than what it is available (in case of having a previous automation), and then implement the technologies that allow the future use of the "Internet of Things".

Although, at the moment in which one wants to carry out this activity, the company may does not have initial data of the most relevant issues, and it is convenient to apply certain techniques and theories of how to find and improve the execution of work within the processes of the company. In spite of other theories and many more techniques currently applicable by companies worldwide; it never discomforts anyone when one mentions the most known and used items, such as:

- Fishbone - Ishikawa diagram, Pareto chart, brainstorming;

- Quality in supply chain, measurement of customer satisfaction;

- Statistical process control, control charts, acceptance of samples, and QFD.

Once the possible problems have been identified within any internal and even external process of the company, it is necessary to review the information and check if there are possible correlations between them or if they are independent. By doing this, it can be shown if the IoT and the automation of the processes can be carried out jointly for some areas.

Within this point, as a recommendation we can mention that consulting and even enlisting more people will contribute to see different points of view and get much faster to the desired result.

\section{Focus on Solving a Problem}

Having pointed out the above points, due to the collected information available, the desire to "fix" or solve everything with a single project, at the beginning could be a big mistake because it may take a little longer than expected to visualize a solution. It is better to use certain theories to eliminate certain problems that should be undesirable such as waiting times, inactivity, system efficiency, etc. For this as a first approximation we have:

- OEE, TOC

- TQM, Lean Manufacturing, TPM, Kanban, STOW

Once made certain calculations and adjustments to the first approximation of the desired environment, optimization, automation and the IoT come into action, but seen in a pragmatic way, the focus on solving a problem has to end with the implementation of the so-called "pilot plan", where the commitment to carry out to improve a process is discretionary, so that even when working on it, this work does not interrupt the daily work of the 
company. Before proceeding with the following points within this element, we have to mention:

a) Do a little research, because one could have too much information and many ideas especially on how to solve a problem. Therefore, one has to address possible solutions, of course, without neglecting any idea. At this moment the search for information is aimed at knowing what solutions exist in the market for a specific problem.

Furthermore, knowledge of how other companies with similar problems or with similar implementations of automation and "Internet of Things" have managed the deployment of new technologies will help to better understanding the IoT environment, and make more efficient approaches with technology companies that support the implementation of these systems.

b) Organize the information, after completing the previous item, one will get many ideas and provide a greater knowledge on how to solve the problem chosen for the analysis, so it is necessary to make an order for each of them. The advisable point is to realize a matrix where the information that has different forms can be easily understood, and it can be used in order to obtain the wished result. Even, not being an expert in issues related to ICT, "Internet of Things", networks, cloud computing, fog computing and the use of each of them, at least have a better perspective of what types of paths exist in order to reach the changes and, above all, if there are existing or non-existing "path", companies or components are capable of fulfilling the company requirements.

c) Knowing potential partners - this is strongly related to the previous point. In this case it is about approaching potential partners or companies with the ability to provide the service to implement an automation at the first level or small scale, and also offer the maintenance of an "open door" for the application of the IoT as a new or future system. Having strategic partners includes knowing what we want and hope to improve. Although during the first approaches they are usually very general questions, this kind of meetings can "clarify" the ideas to the point of knowing what type of components may be necessary for our new systems. Each service provider has different ways of solving a problem and components to install and operate an IoTbased system. It depends on the ability by which the project team is able to carry out the evaluation of each of the possible solutions, and that is why third-party leverage is of utmost importance.
In addition, it is remarkable to remember that the aforementioned literals have a correspondence, that is, together they form a cycle that can be fine-tuned as we get closer to what we are looking for, in a similar way to what an engineering department does when making a design. In the same way, for the execution of the literal c), the exposed steps in Figure 1 Fundamental Aspect of Negotiation based on Information are useful and applicable.

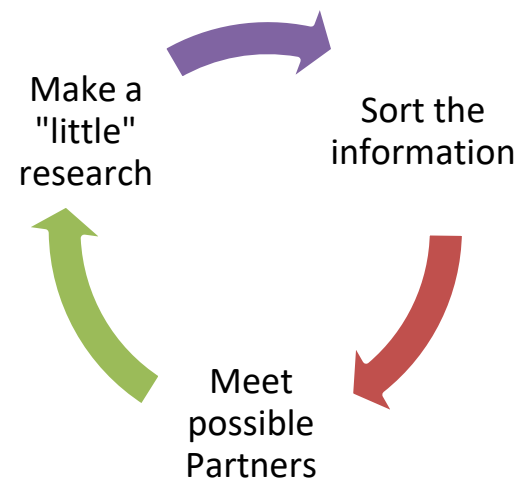

Figure 2. Approaching Partners Cycle.

\section{Prepare and Execute a Simulation}

At this point and after compiling and analyzing the existing information, the next step before launching a "real life" implementation, it is convenient to simulate the processes, both existing and with the changes that have to be made, which will allow us to obtain an approximation of the result. It is worth noting that the simulation will give us a possible approximation depending on the variables applied. This terminology is used because it will be a new system and the simulation is carried out on a computer to predict the values, there may be values or variables that may appear while the implementation is running but also, the variation and variables can be managed through the use of project management methodologies.

It should be clear that this is a proposal stage and, as such, performing a simulation with an implementation on a mobile device or desktop computer and displaying the result in real-time by executing operations in a process would be costly, especially considering a stage where top management has to decide whether or not to allocate a specific amount of money to put a pilot IoT system in pilot mode. Moreover, the contacted companies, according to the previous point, can help to perform realistic simulations or at least virtual ones. Specialized enterprises will execute them only if they perceive that there is a serious probability of conducting an implementation, and this depends on the negotiating skills of the project manager. 
On the other hand, there are the so-called DEMOS, which service companies (investigated in the previous point) can provide during a specific trial period, and there are also programs where one can run a process simulation. This work should be treated as a starting point for the implementation of an "Internet of Things" system. We recommend showing two (02) fundamental aspects:

a) The current scenario; in this scenario, the actions performed during the execution of the operations of a process are shown according to the previous information survey. For this simulation, it should be remembered that by having more information about the processes and operations/activities necessary to produce or execute a service, the precision of the model will be more real.

b) Alternative scenario; in the first stage we have to have the support of senior management, we have to show the scenario of how the process would work if we had the information first hand, and how resources could be optimized, and avoid failures with industry 4.0 .

As mentioned above, the technical leader or project manager has to show the internal advantages that would imply the use of IoT within the company, and especially the competitive advantages created from a deployment. Perhaps in this first approach, the project team has to make use of the techniques, methods, and concepts aforementioned that would have been impossible to detect and optimize without the information and the initial and necessary data.

\section{Define Which Kind of Cooperation Model is Necessary}

According to Guide to IoT Innovation: SMEs focus on some models that we can use in order to start up an IoT project and implementation, among which we can mention [6] :

a) 3rd party full-service provider

b) Corporate Ventures

c) Company Builder/Agency

d) Strategic Partnership

e) Incubator/accelerator

f) Innovation Labs/Spin-off programs

g) Direct start up engagement

h) Ecosystem innovation

i) Open innovation

When considering the differences, kind of communication, pros and cons can the Guide to IoT Innovation: SMEs focus, IoT Analytics $\mathrm{GmbH}$ can be consulted, and it is eligible manner to give an easy approach to them. Depending on the type of company that a project of IoT implementation is carried out, there are three kinds of model cooperation that have given a good result according to the high success rate: 3rd party full-service provider, Corporate Ventures and Strategic Partnership. How the PM can choose one of those great possibilities will depend on [8] :

a) The inner vision of the company, CEOs, manager or owner about the knowledge management;

b) The investment capability;

c) The human resources availability of the company;

d) The technology and IT platform that already exist within the company;

e) The ability of adaption to the change.

\section{Choose a Partner}

This step clearly depends on the hiring of companies and the internal laws of each country, which can be mentioned as part of the generalities to help one have a better idea of the type of service he/she should expect to obtain:

1. In case the company does not have its own IP, the creation of an IPv6 is [5].

2. The type of machinery and equipment to be replaced has characteristics for future connectivity with an "Internet of Things" system;

3. The ease of using service providers or the ability to create clouds and fog for the application of what is called "cloud and fog computing";

4. In case of having previously installed engineering systems of certain suppliers, for example: Dassault System or Siemens, etc., the suppliers can guarantee the connectivity of the equipment with those platforms, so, the future costs in the implementation could be reduced and one can take advantage of the existing platform;

5. The operational capacity to provide maintenance and after-sales assistance after delivery of their products (hardware and software);

6. Offer training to users, if it is necessary;

7. Deliver a complete plan, by stages, execution times, implementation, and verification of the system.

\section{Start the Pilot Plan}

Given the size and import of this type of implementation, since a specific recommendation is to treat this venture as a project, we have mentioned that under the parameters of project management, among which we have two (02) known: PMI and PRINCE2, there are well-defined methodologies for the development and execution of projects, in such a way that progress, traceability and, above all, the 
lessons learned from this plan, are the basis for full deployment in all company's processes.

At this point the most relevant factor can be how or what kind of people should be part of the team. Based on the literature and the complexity that can be the IoT system implementation, some general ideas are suggested:

$\checkmark$ People who know about IT/ITC tools;

$\checkmark$ Technicians or engineers that have experience with the process or system that one wants to change or transform using the IoT;

$\checkmark$ Engineers or programmers with some experience in testing, evaluation and validation application or software environment;

$\checkmark$ People who have shown commitment in the work, who can learn easily and do not have resistance to the change;

$\checkmark$ Finally, choose a leader who can solve the problems and has the ability to create a friendly environment.

In addition to this point, we have to keep in mind that IoT implementation will bring changes and fears from employees' perspective, so before hiring new employees the resources department has to assess how existing employees can "fit" the new reality. Furthermore, the categorization of skills is split into two well-known groups: hard and soft skills. Hard skills are related to a particular field like academic qualification, or computer skills. Soft skills are more like social skills and employment qualities which are not easy to quantify.

After the evaluation, the employees can be split according to their skills and capability, and it will be easy to give training according to each necessity. Only if specific knowledge is needed, new employees can be hired or a third party can be hired to overcome these drawbacks.

\section{Process Application}

In order to illustrate the step aforementioned, the following example will be developed:

Suppose that a company would like to improve the decision making about hiring people for QA/QC department, the company already has installed the any kind of ERP/MRP system. It is considered medium enterprise and has its own IT department services.

1. Business / IoT Goal: Facilitate decision-making on the convenience or need to hire personnel in the operative part of the quality control department.

Mapping of the route to follow: at this point we will draw the line that will follow this first stage of implementation.

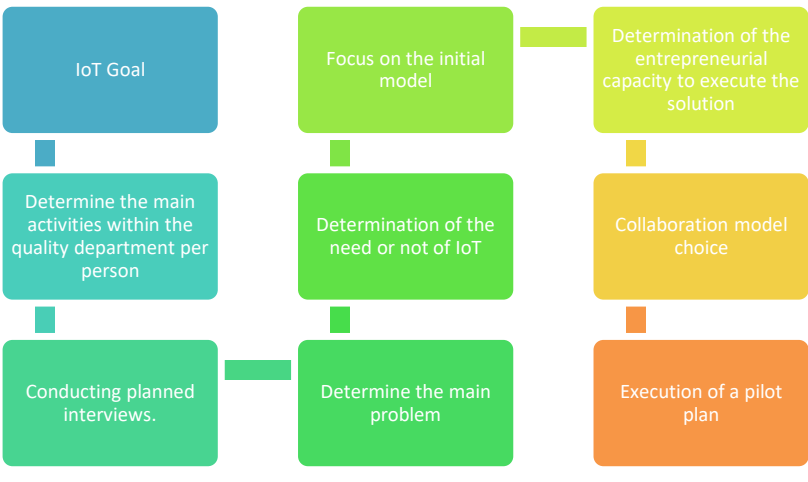

Figure 3. Mapping

2. Determination of activities: for this part we use the following questions:

Table 1. Example to Determine the Main Activities

\begin{tabular}{|c|c|}
\hline Question/Idea & Answer \\
\hline $\begin{array}{l}\text { What is the } \\
\text { purpose of the } \\
\text { department? }\end{array}$ & $\begin{array}{l}\text { ensure that the materials, processes } \\
\text { and / or products meet the criteria } \\
\text { defined in a standard, specification or } \\
\text { standard }\end{array}$ \\
\hline $\begin{array}{l}\text { What } \\
\text { activities does } \\
\text { the staff do? }\end{array}$ & $\begin{array}{l}\text { - Receipt of the inspection / test } \\
\text { requirement (Customer's internal } \\
\text { requirement, work order, technical } \\
\text { specification, standards, and } \\
\text { standards). } \\
\text { - Assignment of personnel for } \\
\text { inspection / testing } \\
\text { - Preparation of equipment and / or } \\
\text { tools, when necessary, for inspection } \\
\text { / testing. } \\
\text { - Execution of the inspection / test. } \\
\text { - Determination, verbal, at the } \\
\text { compliance site or not. } \\
\text { - Preparation of the Inspection Report } \\
\text { / Field Report / Protocol. }\end{array}$ \\
\hline $\begin{array}{l}\text { Are all areas } \\
\text { covered for } \\
\text { QA and QC? }\end{array}$ & $\begin{array}{l}\text { - There are processes not covered, } \\
\text { such as: } \\
\text { - Preparation, manufacture and } \\
\text { assembly of auxiliary systems: } \\
\text { referred to pipes. } \\
\text { - Preparation and assembly } \\
\text { Electrical and electronic system. } \\
\text { - Recently, a supervisor for the area } \\
\text { of cathodic protection and painting } \\
\text { was hired. }\end{array}$ \\
\hline
\end{tabular}

3. Conduct of planned interviews: this point is the equivalent to point 3 of the approach of the previous chapter, which refers to the search for support and consultation. In the same way, we provided some questions as an example. Also, at this point one has to gather information for the simulation. 
Table 2. Example of Main Question to get Information

\begin{tabular}{|l|l|}
\hline \multicolumn{1}{|c|}{ Questions } & \multicolumn{1}{c|}{ Answers } \\
\hline $\begin{array}{l}\text { Can I quantify the } \\
\text { time that is used } \\
\text { per activity? }\end{array}$ & $\begin{array}{l}\text { In general, yes, depending on the } \\
\text { type of control exercised in the } \\
\text { facilities and whether they use } \\
\text { electronic equipment or not. }\end{array}$ \\
\hline $\begin{array}{l}\text { Who makes the } \\
\text { hiring requests? }\end{array}$ & $\begin{array}{l}\text { The head of the quality } \\
\text { department according to the needs } \\
\text { of the different areas, this activity } \\
\text { is reactive. }\end{array}$ \\
\hline $\begin{array}{l}\text { Are the activities } \\
\text { registered by the } \\
\text { staff? }\end{array}$ & $\begin{array}{l}\text { The record that is maintained is } \\
\text { documentary / digital in report } \\
\text { formats (Word), not in a specific } \\
\text { platform or application. }\end{array}$ \\
\hline $\begin{array}{l}\text { Are the } \\
\text { inspections } \\
\text { scheduled in } \\
\text { advance? }\end{array}$ & $\begin{array}{l}\text { The request is made by email } \\
\text { requesting a specific inspection, } \\
\text { and is serviced according to } \\
\text { availability. }\end{array}$ \\
\hline $\begin{array}{l}\text { Do you know } \\
\text { when an activity } \\
\text { end? }\end{array}$ & $\begin{array}{l}\text { An activity ends once the report } \\
\text { or inspection report or quality } \\
\text { control in the field has been } \\
\text { issued. }\end{array}$ \\
\hline $\begin{array}{l}\text { It is known that } \\
\text { activities take } \\
\text { more time? }\end{array}$ & $\begin{array}{l}\text { It is known that there is a delay in } \\
\text { the delivery of field inspection } \\
\text { reports. }\end{array}$ \\
\hline
\end{tabular}

4. Determination of the main problem: at this moment we have to be prepared to determine what the problem is and if it can be found through the use of IoT, it is also the point of evaluating our first premise of the IoT objective, because it is an example practice that the concepts are seen. The problem may be closer to reality, because when one wants to have a better approximation, a greater amount of information is required. "It is not known and cannot currently determine the real need to hire personnel to perform the activity of quality control and quality assurance, in addition to not realizing the occupation of each member of the department."

5. Determination of the need or not of an IoT system represents the relationship which focuses on solving the problem. At this point, the need to use the concept of IoT will be taken for granted, based on the fact that previous activities were carried out in which certain theories mentioned in the previous chapter were put into the execution of works, which aimed to reduce bottlenecks and would help expedite inspections.

What is worth mentioning is that the approach should be made that the problem is recurrent in other areas and not only in the quality department, for which it is recommended to return to point 1 . This relates to know a future if the investment in A plans could have the same solution for other departments.
As additional information, and only for this specific case, we can realize that the presentation of data in real time is not necessary.

6. Prepare and execute a simulation: for the preparation of the simulation, although some information has been generated, it is best to select and tabulate the necessary data, and use the field observation and the recording of activities as a function of time, in case that we do not have these statistics. This will lead to the model and the simulation being the closest to reality. As the main points we can mention:

Table 3. Main Data Requires

\begin{tabular}{|c|c|c|l|}
\hline $\begin{array}{c}\text { Execution } \\
\text { time }\end{array}$ & $\begin{array}{c}\text { Maintenance } \\
\text { frequency }\end{array}$ & $\begin{array}{c}\text { Report the } \\
\text { completion } \\
\text { time }\end{array}$ & Staff age \\
\hline Break time & $\begin{array}{c}\text { Staff } \\
\text { commuter } \\
\text { time }\end{array}$ & $\begin{array}{c}\text { Number of } \\
\text { requests } \\
\text { attended per } \\
\text { day }\end{array}$ & $\begin{array}{c}\text { Equipment } \\
\text { available }\end{array}$ \\
\hline $\begin{array}{c}\text { Time applied } \\
\text { in } \\
\text { maintenance }\end{array}$ & $\begin{array}{c}\text { Type of } \\
\text { activity }\end{array}$ & $\begin{array}{c}\text { Statistics of } \\
\text { illness and / } \\
\text { or absence }\end{array}$ & Downtime \\
\hline
\end{tabular}

\begin{tabular}{|c|c|c|c|c|c|c|c|c|}
\hline & \multicolumn{3}{|c|}{ Welding Inspector 1 } & \multicolumn{4}{c|}{ Welding Inspector 2 } \\
\cline { 2 - 9 } Day & $\begin{array}{c}\text { Execution } \\
\text { time (hr) }\end{array}$ & $\begin{array}{c}\text { Number } \\
\text { of } \\
\text { requests } \\
\text { attended } \\
\text { per day }\end{array}$ & $\begin{array}{c}\text { Report the } \\
\text { completion } \\
\text { time (hr) }\end{array}$ & $\begin{array}{c}\text { Downtime } \\
\text { (hr/day) }\end{array}$ & $\begin{array}{c}\text { Execution } \\
\text { time (hr) }\end{array}$ & $\begin{array}{c}\text { Number of } \\
\text { requests } \\
\text { attended } \\
\text { per day }\end{array}$ & $\begin{array}{c}\text { Report the } \\
\text { completion } \\
\text { time (hr) }\end{array}$ & $\begin{array}{c}\text { Downtime } \\
\text { (hr/day) }\end{array}$ \\
\hline 1 & 4 & 1 & 7,5 & 1,78 & 3 & 1 & 5,8 & 1,60 \\
\hline 2 & 2 & 2 & 3,5 & 1,48 & 2,6 & 2 & 3,5 & 1,48 \\
\hline 3 & 6 & 1 & 5 & 1,72 & 4,2 & 1 & 5 & 1,86 \\
\hline 4 & 4 & 1 & 3,2 & 1,98 & 4,3 & 1 & 3,2 & 1,98 \\
\hline 5 & 5 & 1 & 3 & 2,19 & 5,6 & 1 & 3 & 2,19 \\
\hline 6 & 3 & 2 & 4 & 2,30 & 2,8 & 2 & 4 & 2,30 \\
\hline 7 & 0,5 & 6 & 1 & 2,15 & 0,65 & 5 & 1 & 2,15 \\
\hline 8 & 4,2 & 1 & 5 & 2,30 & 1 & 2 & 5 & 2,30 \\
\hline 9 & 3,5 & 1 & 3 & 1,80 & 3,3 & 1 & 3 & 1,80 \\
\hline 10 & 3,2 & 1 & 2,8 & 2,50 & 3 & 2 & 2,8 & 1,73 \\
\hline 11 & 3,3 & 1 & 3 & 2,00 & 3,74 & 1 & 3 & 2,00 \\
\hline 12 & 3,2 & 1 & 3,1 & 1,85 & 3,1 & 2 & 3,1 & 1,85 \\
\hline 13 & 4,2 & 1 & 2,1 & 2,95 & 4,3 & 1 & 2,1 & 2,95 \\
\hline 14 & 2,1 & 3 & 1 & 1,64 & 2,5 & 3 & 1 & 1,64 \\
\hline 15 & 2,3 & 3 & 1 & 1,45 & 2,4 & 2 & 1 & 1,45 \\
\hline 16 & 2 & 3 & 1 & 2,28 & 2,1 & 3 & 1 & 1,93 \\
\hline 17 & 2 & 3 & 1,1 & 2,30 & 2 & 3 & 1,1 & 2,30 \\
\hline 18 & 2,4 & 3 & 1,2 & 1,48 & 2,4 & 3 & 1,2 & 1,48 \\
\hline 19 & 1 & 5 & 1 & 1,75 & 1 & 5 & 1 & 1,75 \\
\hline 20 & 1,2 & 4 & 2 & 1,85 & 1,2 & 3 & 2 & 1,85 \\
\hline 21 & 1,4 & 4 & 2 & 1,95 & 1,4 & 4 & 2 & 1,95 \\
\hline 22 & 1,5 & 4 & 1,1 & 2,15 & 1,6 & 4 & 1,1 & 2,15 \\
\hline 23 & 0,5 & 5 & 2 & 1,80 & 0,5 & 6 & 2 & 1,80 \\
\hline Total & 62,5 & 57 & 59,6 & 45,62 & 58,69 & 58 & 57,9 & 44,47 \\
\hline Average & $\mathbf{2 , 7 2}$ & 2,48 & $\mathbf{2 , 5 9}$ & $\mathbf{0 , 3 6}$ & $\mathbf{2 , 5 5}$ & 2,52 & $\mathbf{2 , 5 2}$ & $\mathbf{0 , 3 4}$ \\
\hline Standard & $\mathbf{1 , 4 4}$ & & $\mathbf{1 , 6 5}$ & $\mathbf{1 , 9 8}$ & $\mathbf{1 , 3 2}$ & & $\mathbf{1 , 4 5}$ & $\mathbf{1 , 9 3}$ \\
\hline Dev. & & & & & & & & \\
\hline & & & & & & & & \\
\hline
\end{tabular}

Figure 4. Input Data

Now, simulation will be done by using PROMODEL 7.5, in order to figure out the QC/AC department needs. Furthermore, it is necessary to establish some consideration and assumptions:

- The model will be running for 207 hours that is the equivalent of working 9 hours during 23 days.

- Normal statistical model has been used to simulate the situation within each stage. 
- The inspection requests have been rounded (Arrivals/day) to 3, due to the requests (clients) are units.

- The frequency for arrivals or inspection requests every 8 hours, that means a normal labour day.

Table 4. Individual Capacity per Activity

\begin{tabular}{|c|c|c|c|c|}
\hline Location & $\begin{array}{c}\text { \% } \\
\text { Ope. }\end{array}$ & $\begin{array}{c}\text { \% } \\
\text { Ina. }\end{array}$ & $\begin{array}{c}\text { \% } \\
\text { Bl. }\end{array}$ & $\begin{array}{c}\text { \% } \\
\text { D.T }\end{array}$ \\
\hline Weld. inspector 1 & 63,38 & 0,07 & 13,83 & 22,72 \\
\hline Weld. inspector 2 & 68,66 & 0,13 & 8,56 & 22,65 \\
\hline Paper work insp 1 & 65,63 & 34,37 & & \\
\hline Paper work insp 2 & 58,95 & 41,05 & & \\
\hline
\end{tabular}

Table 5. Rate Summary

\begin{tabular}{|c|c|c|c|}
\hline Entity & Output & $\begin{array}{c}\text { Average Time } \\
\text { in the System } \\
\text { (Min) }\end{array}$ & $\begin{array}{c}\text { Average Time } \\
\text { in Operation } \\
\text { (Min) }\end{array}$ \\
\hline Client & 100,00 & 805,08 & 659,78 \\
\hline
\end{tabular}

7. The following points of our mapping are directly inherent to the commercial situation and the decisions of senior management. In our case it is known that part of the current situation of the company, the history of this type of technological entrepreneurship (IT) and the current majority occupation, the ideal cooperation model to follow is that of the STRATEGIC PARTNERSHIP, and the main decision for this recommendation is that the company has a strategy management department in charge of the company's IT systems.

As additional data, it is necessary to assess which platforms exist within the company to choose the associated company. In this case a company is to be recommended that can be linked to the ERP/MRP platform, since it is the company that owns the design.

8-9. Undertake the pilot plan, until now we have to be prepared to face the challenges of carrying out a small-scale pilot plan.

Moreover, as the technology change every year, applying the agile methodology allows the company and the partner collaborator to adjust and assume new challengers according to the needs and available tech.

\section{Recommendations}

In terms of future research, perhaps more emphasis should be placed on specific issues such as safety within an Industry 4.0 ecosystem, where the flow of data is constant and very large.

As a general recommendation, it can be mentioned the fact that develop and economic or financial approach, it is necessary, not only to know the amount of investment, but to know the cash flow of the project or initiative. It can be reached according to the collaboration model that project managers decide to choose. IoT it is not only for a specific field, it can be useful in many areas such as human resources, too.

\section{Conclusion}

The lack of specific guidelines which can help people in an IoT deployment, middle management is needed and useful, especially for those who do not know how to start.

On the other hand, having an idea about how to start an IoT project implementation helps us to be sure about the different needs of the enterprise, while trying to group or categorize the diverse problems within a company, which allows having a better idea about the needs, behaviors, and path in order to achieve better efficiency and effectiveness

\section{References}

[1]. Abdel-Basset, M., Manogaran, G., \& Mohamed, M. (2018). Internet of Things (IoT) and its impact on supply chain: A framework for building smart, secure and efficient systems. Future Generation Computer Systems, 86, 614-628.

[2]. Badiru, A., Badiru, A., \& Badiru, A. (2007). Industrial project management: Concepts, tools, and techniques. CRC Press.

[3]. Dave, E. (2011). How the next evolution of the internet is changing everything. The Internet of Things.

[4]. Cotteleer, J. H. (2015). Inside of the Internet of Things. Deloitte University Press, 30-36.

[5]. Heidt, E.T. (2017). Planning Guide for the Internet of Things. Gartner. Retrieved from:

https://www.gartner.com/binaries/content/assets/event s/keywords/catalyst/catus $8 / 2017$

planning guide for the iot.pdf [accessed on: 05 January 2020].

[6]. Gartner Group. (2017). Leading the IoT: How to lead in a connected Wolrd. Mar Hung (Editor).

[7]. King, S. C. (2016). Unerstanding the Industrial Design. En Chapter 1 (págs. 1-35). O'REILLY.

[8]. Kranz, M. (2016). Building the internet of things: Implement new business models, disrupt competitors, transform your industry. John Wiley \& Sons.

[9]. Fernández, M. Á., \& Pajares, R. (2017). La digitalización del mundo industrial. Economía industrial, (405), 41-45. 